See Article page XXX.

\section{Commentary: Is it the tricuspid valve, is it the right ventricle? Have we improved?}

\author{
Carlos A. Mestres, MD, PhD, FETCS, ${ }^{\mathrm{a}, \mathrm{b}}$ and \\ Daniel Pereda, MD, $\mathrm{PhD}^{\mathrm{c}}$
}

The left side of the heart received predominant attention by researchers and clinicians for decades, whereas the right side was consistently neglected when treating valvular disease. However, since the early experiments of Vatner and Braunwald $^{1}$ on the effects of chronic heart failure on the right ventricle $(\mathrm{RV})$, it became consistently clear that there was something wrong with the RV in relation with its changes in pressure and dimensions under different conditions, in other words, with the nonfailing and the failing RV.

The surgical treatment of right-sided valvular lesions, isolated or in the context of treatable left-sided lesions, especially mitral, is still a matter of debate. This is an old story, and we are still searching for good answers to many questions. Much knowledge on the tricuspid valve (TV) and the RV has been accumulated in recent years to understand the significance of TV dysfunction and what the differences between organic and functional disease are. ${ }^{2}$ One of these questions that is still active is that from Duran and colleagues, ${ }^{3}$ who wondered whether TV repair was necessary at the time of surgery for left-sided lesions. They already emphasized the need for correction of organic disease and to address functional tricuspid regurgitation if

From the a Department of Cardiac Surgery, University Hospital Zürich, Zürich, Switzerland; 'bepartment of Cardiothoracic Surgery, The University of the Free State, Bloemfontein, South Africa; and ${ }^{\mathrm{c}}$ Department of Cardiovascular Surgery, Hospital Clinic de Barcelona, University of Barcelona, Barcelona, Spain.

Disclosures: Dr Mestres discloses the following: consulting fees, Edwards Clinical Events Committee (CEC) and Cytosorbents Corp. Dr Pereda discloses the following: proctoring and consulting fees for Edwards Lifesciences.

The Journal policy requires editors and reviewers to disclose conflicts of interest and to decline handling or reviewing manuscripts for which they may have a conflict of interest. The editors and reviewers of this article have no conflicts of interest.

Received for publication Nov 1, 2021; revisions received Nov 1, 2021; accepted for publication Nov 1, 2021.

Address for reprints: Carlos A. Mestres, MD, PhD, FETCS, Department of Cardiac Surgery, University Hospital Zürich, Rämistrasse 100, CH-8091 Zürich,

Switzerland (E-mail: Carlos.Mestres@usz.ch).

J Thorac Cardiovasc Surg 2021; $\mathbf{\square}: 1-2$

$0022-5223 / \$ 36.00$

Copyright (c) 2021 by The American Association for Thoracic Surgery

https://doi.org/10.1016/j.jtcvs.2021.11.002

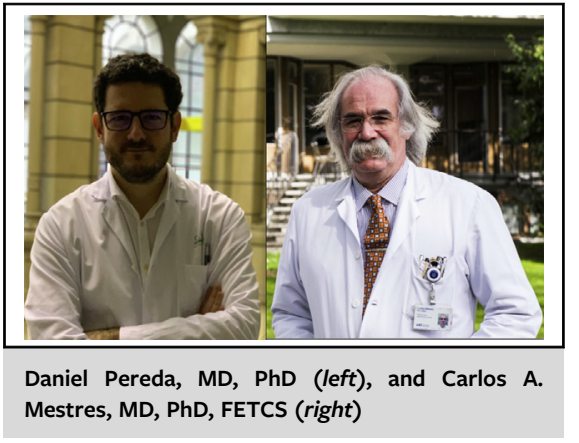

\section{CENTRAL MESSAGE \\ Functional and structural disease \\ must be openly addressed in \\ tricuspid surgery. Patients with \\ severe functional regurgitation \\ must be earlier referrals, as it \\ impacts on survival if \\ uncorrected.}

pulmonary pressure and resistances were not expected to significantly decrease after surgery.

It seems that we have learned. In this issue of the Journal, Elgharably and colleagues ${ }^{4}$ from the Cleveland Clinic analyze a series of 62 patients who underwent isolated primary and reoperative surgery, repair, or replacement of the $\mathrm{TV}$, with $73 \%$ reoperative surgery. The authors produce a myriad of data and, as expected, complex statistics in an elegant and well-elaborated contribution. Despite some acknowledged limitations, especially related to a heterogeneous small sample and patient selection, the main conclusions are of extreme importance today. First, the authors make clear the difference in behavior of the organic and functional tricuspid dysfunction. Second, despite this pathophysiologic differentiation, RV function was similar but RV morphology and clinical manifestations of RV failure were not, with greater impact of functional disease. This suggests more complex mechanisms than RV dysfunction alone are at play. ${ }^{1}$ Third, perioperative results were equally good; however, survival was worse in the functional group. The take-home message is clear; the authors verbalize what we "know" and have in mind for decades, that more tricuspid surgery should be performed and that patients with functional tricuspid regurgitation must be referred earlier for surgery. 
Recent contributions addressed this problem, ${ }^{5-7}$ although with slightly less-sophisticated analytical methods. The chronic misconceptions on functional tricuspid regurgitation $^{2}$ are now being clarified, especially in a time when much investigation and investment goes into the transcatheter approach to the TV, both for percutaneous repair and replacement. Elgharably and colleagues ${ }^{4}$ have produced very relevant information that helps to integrate cumulative knowledge for more than 4 decades and to shed more light on a valve and disease that may not be "forgotten" or "challenging" any longer. This supports our view that important things should not be left unattended. ${ }^{8}$

\section{References}

1. Vatner SF, Braunwald E. Effects of chronic heart failure on the inotropic response of the right ventricle of the conscious dog to a cardiac glycoside and to tachycardia. Circulation. 1974;50:728-34.
2. Taramasso M, Vanermen H, Maisano F, Guidotti A, La Canna G, Alfieri O. The growing clinical importance of secondary tricuspid regurgitation. J Am Coll Cardiol. 2012;59:703-10.

3. Duran CM, Pomar JL, Colman T, Figueroa A, Revuelta JM, Ubago JL. Is tricuspid valve repair necessary? J Thorac Cardiovasc Surg. 1980;80:849-60.

4. Elgharably H, Ibrahim A, Rosinski B, Thuita A, Blackstone EH, Collier $\mathrm{PH}$, et al. Right heart failure and patient selection for isolated tricuspid valve surgery. J Thorac Cardiovasc Surg. XXX, 2021 [Epub ahead of print].

5. Huckaby L, Seese L, Hong Y, Sultan I, Gleason T, Chu D, et al. Concomitant tricuspid valve surgery is beneficial at the time of left-sided valve surgery. $J$ Card Surg. 2021;36:981-9.

6. Pahwa S, Saran N, Pochettino A, Schaff HV, Stulak J, Greason K, et al. Outcomes of tricuspid valve surgery in patients with functional tricuspid regurgitation. Eur J Cardiothorac Surg. 2021;59:577-85.

7. Yilmaz O, Suri RM, Dearani JA, Sundt TM III, Daly RC, Burkhart HM, et al. Functional tricuspid regurgitation at the time of mitral valve repair for degenerative leaflet prolapse: the case for a selective approach. J Thorac Cardiovasc Surg. 2011;142:608-13.

8. Mestres CA, Sromicki J, Vogt PR. In the operating room, do not leave important things unattended. J Card Surg. 2021;36:990-1. 